\title{
THE EFFECT OF ASSISTED VENTILATION ON ARTERIAL CARBON DIOXIDE
}

\author{
Ernest M. Grundy, Mg Tun Shin, Edwafd J. Bennett, and Kanchan P. Patel
}

MANUAL ASSISTANCE of ventilation is a widely taught and commonly practiced anaesthetic technique. It had its origins in cyclopropane anaesthesia. Guedel in $1940^{1}$ recommended "passive respiration" to maintain the adequacy of ventilation. Today the technique of assisting ventilation has been extended to include many anaesthetized patients who are breathing spontaneously. This study was undertaken to see whether and to what degree the arterial carbon dioxide tension is lowered when the breathing of a spontaneously ventilating patient is manually assisted.

\section{METHOD}

Patients of Physical Status ASA I to III undergoing elective operations were premedicated with atropine together with either morphine or hydroxyzine intramuscularly, 45 minutes before induction of anaesthesia. One group was anaesthetized using a circle system with carbon dioxide absorption and a second using a T-piece.

The circle system group consisted of 24 patients with a mean age of 19 years (range 8-40 years) and a mean weight of $47 \mathrm{~kg}$ (range 23-100 kg). They were induced with a hypnotic dose of thiopentone followed by $1 \mathrm{mg} / \mathrm{kg}$ of succinylcholine intravenously to permit introduction of a snugly fitting cuffed tube into the trachea. On return of spontaneous respiration anaesthesia was stabilized with halothane added to a 50 per cent mixture of oxygen and nitrous oxide which was delivered into a circle system with carbon dioxide absorption.

The $T$-piece group (restricted to patients under $50 \mathrm{lb} .(23 \mathrm{~kg}$ ) in weight) consisted of 18 patients with a mean age of four years (range one to eight years) and a mean weight of $17 \mathrm{~kg}$ (range 9-23 kg). They were induced with halothane in a mixture of 50 per cent oxygen and nitrous oxide delivered with a Rees modification of Ayre's T-piece (Mapleson " $F$ " system). ${ }^{2}$ When the patient was unconscious, succinylcholine $\mathrm{lmg} / \mathrm{kg}$ was given intravenously to permit introduction of a snugly fitting non-cuffed tracheal tube and then a gauze pack was placed in the mouth and pharynx. On return of spontaneous respiration anaesthesia was stabilized with halothane carried in a fresh gas flow of at least $400 \mathrm{ml} / \mathrm{kg}$ (to prevent partial re-breathing) delivered to the Mapleson " $F$ " system.

In all patients in both groups arterial cannulation was indicated either by the operation (e.g., major orthopaedic) or by the condition of the patient (e.g., sickle cell) and was achieved percutaneously with the patient breathing spontaneously

Ernest M. Grundy, F.F.A.R.C.S., Mg Tun Shin, M.D., Edward J. Bennett, M.D., and Kanchan P. Patel, M.D. Department of Anesthesiology, Abraham Lincoln School of Medicine, University of Illinois Hospitals, 840 South Wood Street, Chicago, Illinois 60612. 


\section{CIRCLE SYSTEM}

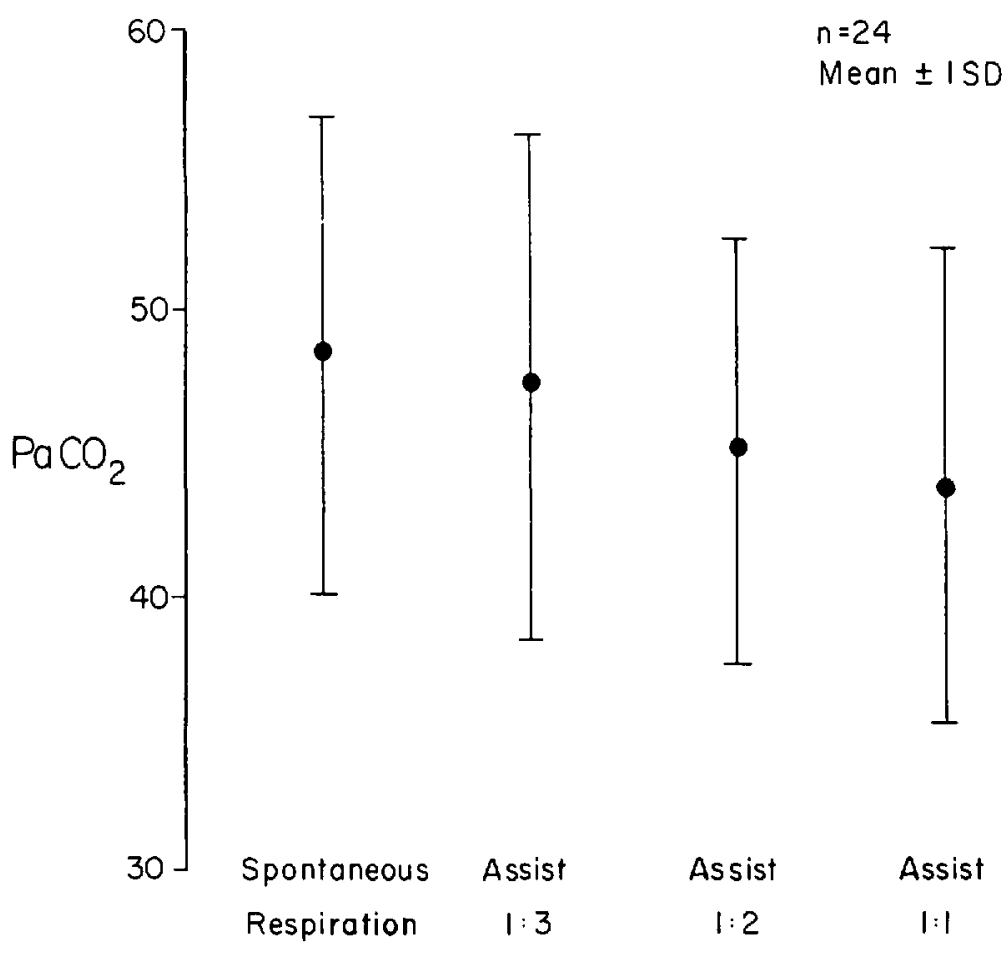

Figure 1. Mean $\mathrm{Paco}_{2}$ with assisted ventilation in circle system.

and while the surgical site was scrubbed and draped. Measurements were commenced after the incision had been made and the method was similar in both groups: with spontaneous respiration, a base line blood gas sample was taken, then every third breath was assisted by manual squeezing of the reservoir bag and an arterial blood sample was taken after 10 minutes. This sequence was repeated with assistance being given to every second breath and then with assistance of every breath. The arterial blood samples were analyzed almost immediately on an IL 313 Blood Gas Analyzer by a technician who calibrated the machine before every reading.

\section{RESULTS}

The mean arterial carbon dioxide tension plus or minus one standard deviation is shown for each of the four modes of ventilation in Figure 1 for the circle system and in Figure 3 for the Mapleson "F" system. In addition the mean change in $\mathrm{Pa}_{\mathrm{CO}_{2}}$ from the spontaneously breathing state to each of the three "assist modes" is shown in Figure 2 for the circle system and in Figure 4 for the Mapleson " $F$ " system.

Statistical analysis using students " $\mathrm{t}$ " test showed that the results for the circle 


\section{CIRCLE SYSTEM}

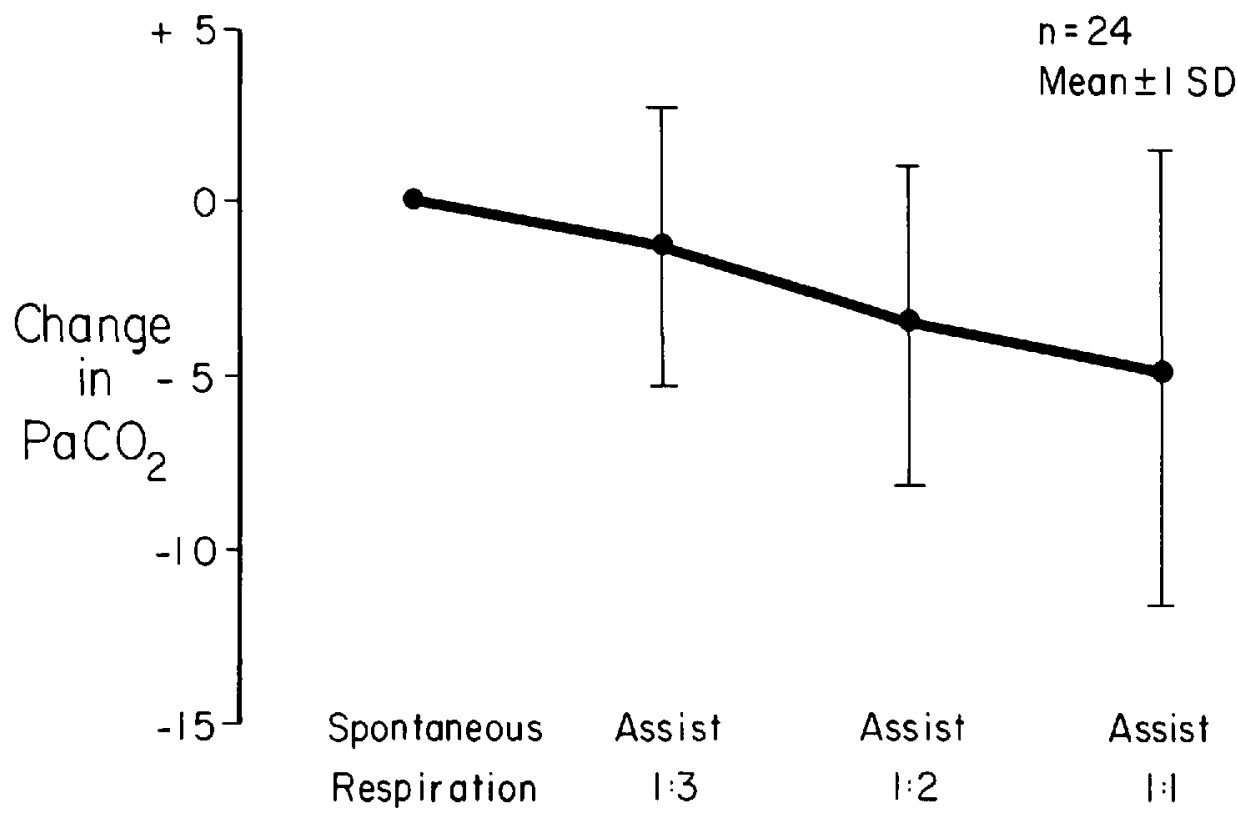

Figure 2. Change in $\mathrm{Paco}_{2}$ with assisted ventilation in the circle system.

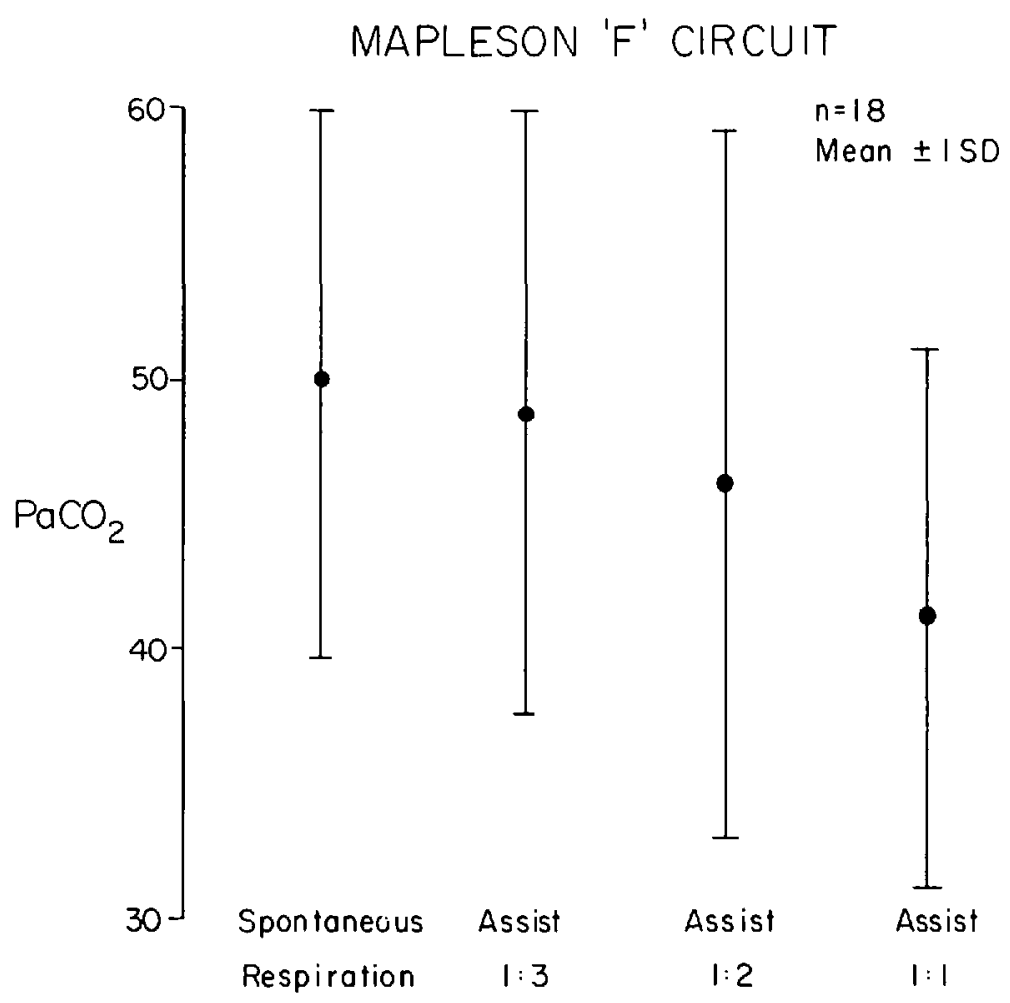

Frcure 3. Mean $\mathrm{Paco}_{2}$ with assisted ventilation in Mapleson " $F$ " circuit. 


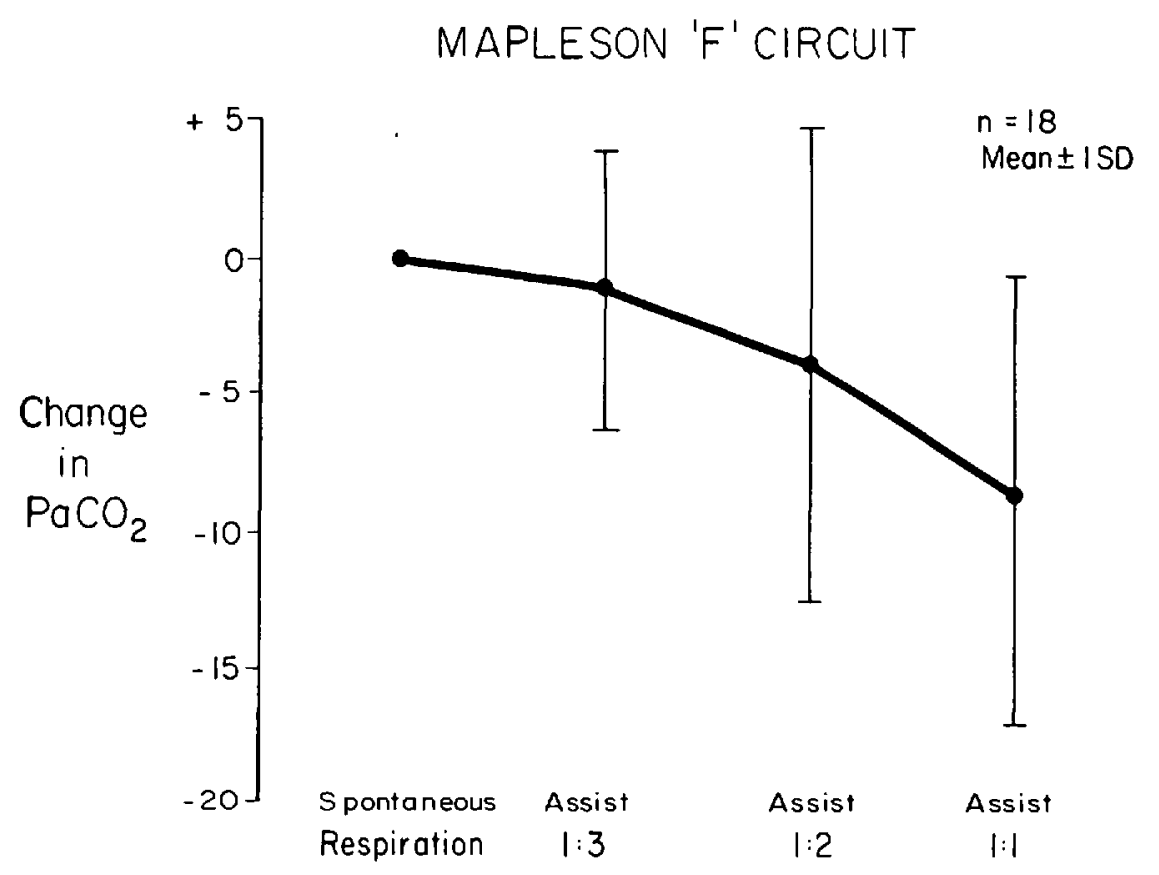

Figure 4. Change in Paco.n with assisted ventilation in Mapleson " $F$ " circuit.

system and the Mapleson " $F$ " system were not significantly different $(p<0.1)$ for the mean $\mathrm{Pa}_{\mathrm{CO}_{2}}$ or the change in $\mathrm{Pa}_{\mathrm{CO}_{2}}$, for each of the four modes of ventilation. Thus the results can be pooled and are presented in Table I. The change from one mode of ventilation to the next barely achieves statistical significance $(\mathrm{p}<0.1>0.05)$.

\section{Discussion}

Maintenance of eucarbia during anaesthesia would be the ideal of most anaesthetic techniques, although this is rarely achieved: a spontaneously breathing patient will hypoventilate and become hypercarbic whilst controlled ventilation is usually associated with hypocarbia unless ventilatory parameters are taken from nomograms, such as that of Radford, ${ }^{3}$ or the fresh gas inflow into the system is limited, ${ }^{4,5}$ dead space or carbon dioxide is added. The technique of "assisting" a spontaneously breathing patient is widely suggested to counteract hypercarbia, but this is only partly borne out by our results which are summarized in Table I. It should be noted that in all three modes there is a considerable chance of producing a rise rather than a fall in the arterial carbon dioxide tension (occurring in 20 per

TABLE I

Combined Results for Assisted Respiration

\begin{tabular}{ccc}
\hline \hline Mean & Mean Fall in $\mathrm{PaCO}_{2}$ & \pm 1 Standard Deviation \\
\hline Assist $1: 3$ & 1.2 torr & 4.5 torr \\
Assist $1: 2$ & 3.6 torr & 6.7 torr \\
Assist $1: 1$ & 6.6 torr & 7.6 torr \\
\hline
\end{tabular}


cent of our cases). The technique depends on the patient initiating the breath and it can be surprisingly easy to pass from assisting to controlling ventilation, especially when one is assisting every breath and these are of small tidal volume. In this study, on four occasions, when changing from assisting every second breath to assisting every breath, there was a fall in $\mathrm{Pa}_{\mathrm{CO}_{2}}$ of 12 torr or more; this is highly suggestive of a change from assisting to controlling of ventilation (of these four cases, three were from the paediatric group).

All the potent inhalational anaesthetic agents, including halothane, produce respiratory depression principally by a direct action on the respiratory center. ${ }^{\theta}$ Thus it is the initiation of respiration rather than the peripheral neuromuscular power of respiration that is depressed. One would expect that by assisting ventilation one would inevitably increase the depth of anaesthesia and hence potentiate the degree of central respiratory depression and increase carbon dioxide retention. Such an increase in $\mathrm{PaCO}_{2}$ was seen in 20 per cent of our cases. However, in the majority a fall was seen, but to below 40 torr in only 30 per cent, presumably because as part of the protocol the concentration of the inhalation agent was reduced when assisted ventilation was instituted, to avoid producing an anaesthetic deeper than necessary. One can speculate that the reduction in the arterial $\mathrm{CO}_{2}$ could be simply due to lightening of the anaesthetic depth and that this single maneuver without the addition of assisted ventilation may explain all of the decrease in $\mathrm{Pa}_{\mathrm{CO}_{2}}$ and may be clinically desirable because it removes the risk of controlling ventilation in error and so producing an inappropriate depth of anaesthesia.

\section{Conclusron}

In a patient who is spontaneously breathing a potent anaesthetic agent and who is not under the influence of a muscle relaxant, assisting ventilation will usually produce a reduction in arterial carbon dioxide tension; however, this is not reliable and is unlikely to produce a carbon dioxide tension below 40 torr. Thus, in those cases where hypercarbia is deemed undesirable, assisted ventilation is not the anaesthetic technique of choice. If it is used, the chances of inadvertently controlling ventilation are lessened if one avoids assisting every breath and preferably every third or alternate breaths should be assisted.

\section{SUMMARY}

The effect on the arterial carbon dioxide tension of assisting spontaneously breathing patients under halothane anaesthesia has been studied. A reduction in $\mathrm{Pa}_{\mathrm{CO}_{2}}$ is usually seen, but it was reduced below 40 torr in only 30 per cent of cases, while a rise was recorded in 20 per cent.

\section{RÉSUMÉ}

Les auteurs ont étudié les effets de l'assistance manuelle à la respiration sur la $\mathrm{Pa}_{\mathrm{CO}_{2}}$ de patients anesthésiés à l'Halothane. On a trouvé en général un abaissement de la $\mathrm{Pa}_{{ }^{\prime} \mathrm{O}_{2}}$, mais cet abaissement était léger puisque 30 pour cent seulement des patients avaient des $\mathrm{PCO}_{2}$ sous 40 Torr. Bien plus, on a observé une élévation de $\mathrm{PCO}_{2}$ chez 20 pour cent des patients assistés manuellement. 


\section{REFERENCES}

1. Guedel, A.E. Cyclopropane anaesthesia. Anesthesiology 1: 13 (1940).

2. Willis, B.A., Pender, J.W., \& Mapleson, W.W. Rebreathing in a T-piece: volunteer and theoretical studies of the Tackson-Rees modification of Ayres T-piece during spontaneous respiration. Brit. J. Anaesth. 47: 1239 (1975).

3. Radforti, E.P. Ventilation standards for use in artificial ventilation. J. Appl, Physiol. 7 : 451 (1955).

4. Bain, J.A. \& SPOerel, W.E. A streamlined anaesthetic system. Canad. Anaesth. Soc. J. 19: 426 (1972).

5. Patel, K.P., Bennett, E.J., Ghundy, E.M., \& Ignacio, A.D. Jr. Paco. and fresh gas flow in a circle system. Anesth. \& Analg. 55 (1976).

6. Munson, E.S., Larson, C.P., Badad, A.A., Regan, M.J., Buechel, D.R., \& Eger, E.I. The effects of halothane, fluroxene and cyclopropane on ventilation: a comparative study in man. Anesthesiology 27: 716 (1966). 